\title{
Empirical Mysteries of the 2016-17 NBA Regular Season
}

\author{
By Thomas M. Fullerton, Jr. , James H. Holcomb ${ }^{\dagger} \&$ \\ Michael L. Jaeger
}

\begin{abstract}
This study examines the on-court performance of the thirty National Basketball Association (NBA) teams during the 2016-17 NBA basketball season. Cross sectional data are employed to analyze wins for the 2016-17 NBA basketball season. Although the results are inconclusive, there is one notable outcome in the form of a negative correlation between team payrolls and victories. Field goal percentage is, similarly, also reliably associated with team wins. In general, the outcomes obtained stand in contrast to those reported in prior analyses conducted for major League Baseball and the National Football League. Replication of this study for the 437 teams in National Collegiate Athletics Association provides an intriguing opportunity for subsequent research.
\end{abstract}

Keywords: National basketball association, team performance.

\section{Introduction}

The National Basketball League produces an increasingly popular product in the United States and abroad. Games are watched, or attended, by millions of fans every year, especially as the league continues to invest overseas. Given that, it is natural to examine what influences win-loss records during the regular season. Prior studies have analyzed variables that impact post-season outcomes (Berri and Eschker, 2005; Wallace, Caudill and Mixon, 2013; Zimmer and Kuethe, 2009), but comparatively little attention has been devoted to the regular season.

This effort examines the potential impacts of both on-court performance measures and several management variables on win-loss records during the 201617 NBA season. The analysis is similar to what has been used in recent studies of Major League Baseball (MLB) regular season outcomes (Fullerton et al., 2014; Peach et al., 2016; Fullerton and Peach, 2016). There are no guarantees, however, that what works for empirical post-mortems of one spectator sport will be applicable to another segment of the entertainment athletics complex.

The study is structured as follows. Section two provides an overview of related studies; section three describes the data and methodology; section four discusses empirical results. The analysis is summarized in the concluding section. A statistical data appendix is included at the end of the document.

\footnotetext{
*Professor, Department of Economics \& Finance, University of Texas at El Paso, USA. ${ }^{\dagger}$ Associate Professor, Department of Economics \& Finance, University of Texas at El Paso, USA. ${ }^{\star}$ Dual Credit Economics Instructor, Franklin High School in El Paso, Texas, USA.
} 


\section{Literature Review}

Several studies examine the impacts of payroll dispersion on team success. Jewell and Molina (2004) focuses on different aspects of MLB and document an inverse correlation between salary dispersion and victories. More recently, Fullerton et al. (2014) provides evidence that payroll dispersion may not affect team win-loss performances. Increases in player salary ranges are not found to hurt team records. As hypothesized, on-field performances are important to the winloss column. Peach et al. (2016) reports evidence that each season should be looked at "in isolation from predecessors," due to parameter heterogeneity. That outcome is confirmed by Fullerton and Peach (2016).

Beri (1999) looks at the NBA regular season statistics and team wins, but does not include salaries in the analysis. The empirical results of this study show there is a correlation between player performance and team wins. That study cautions that player performances can be affected by trades, free agent acquisitions, and/or minutes played. Roster changes may require adjustments to new playing styles and reduced playing times. Berri and Eschker (2005) examines NBA postseasons from 1994-2003. That study finds no evidence of player performances being enhanced during the playoffs. The widespread claim of "Prime-Time Players" found to be fictional.

Katayama and Nuch (2011) analyzes panel data for the NBA regular seasons from 2002 to 2006. Outcomes in that effort indicate that a smaller spread between player salaries positively affects team performance and win-loss records. More specifically, a smaller pay gap is better than paying one-to-three players most of the salary cap and filling the rest of the team with low-paid players. Due to the small number of players on the court compared to the MLB and National Football League (NFL), salary dispersion may not be a factor in causing infighting among NBA teams. In an effort to maximize profits rather than wins, teams may, nonetheless, purchase superstar players to sell more tickets.

\section{Data and Methodology}

Data for the 2016-17 NBA season are analyzed in this study. Regular season team wins are the variable of interest. The regular season has eighty-two games for each of the thirty NBA teams. Because not all teams reach the playoffs, post season games are excluded from the analysis.

Variables employed in this study are listed in Table 1.The left-hand dependent variable is WINS17, the number of wins from the eighty-two games played during the regular season. PTS17 is the average points scored per game during the season. FGPCT17 is the successful percentage of baskets made by each team. PT3PCT17 indicates the percentage of 3-point baskets made beyond the 23 foot 9-inch arc. FTPCT17 signifies the percentage of completed shots at the free throw line following fouls. These four variables summarize team offensive output and are expected to be positively correlated with victories. 
Table 1. Variables and Units

\begin{tabular}{|c|c|c|}
\hline Variable Names & Description & Data Source \\
\hline GP & Games Played & http://www.espn.com/ \\
\hline WINS17 & Games won by the team, a total of 82 games played & http://www.espn.com/ \\
\hline L17 & Games lost by the team, a total of 82 games played & http://www.espn.com/ \\
\hline PTS17 & Season average of points scored by team per game & http://www.espn.com/ \\
\hline FGPCT17 & Season average of successful field goal percentage, any points scored within the 3-point arc, not including free throws & http://www.espn.com/ \\
\hline РТ3РСТ17 & Season average percentage of successful 3-point attempts, any shot beyond the 3-point arch & http://www.espn.com/ \\
\hline FTPCT17 & Season average percentage of successful free throws made at the free throw line & http://www.espn.com/ \\
\hline OREB17 & Season average of rebounds on offensive side per game & http://www.espn.com/ \\
\hline DREB17 & Season average of rebounds on defensive side per game & http://www.espn.com/ \\
\hline REB17 & Season average of total rebounds per game & http://www.espn.com/ \\
\hline AST17 & Season average of total assist per game & http://www.espn.com/ \\
\hline TOV17 & Season average of turnovers per game & http://www.espn.com/ \\
\hline STL17 & Season average of steals per game & http://www.espn.com/ \\
\hline BLK17 & Season average of blocks per game & http://www.espn.com/ \\
\hline $\mathrm{COACH} 17$ & The salary for the head coach during the 2016-17 season in dollars & http://www.basketballinsiders.com/ \\
\hline COACHEXP17 & The total number of years as a head coach & http:/www.basketball-reference.com/ \\
\hline TOTFINE17 & The total of all player fines per team in dollars & http://www.espn.com/ \\
\hline AGE17 & The average age of players per team in years & http://www.basketballinsiders.com/ \\
\hline AGE17SQ & The average age of players per team in years squared & Author Calculations \\
\hline EXP17 & The average number of years the players on the team have played in the NBA & http://www.basketballinsiders.com/ \\
\hline PYRL17 & Total payroll paid out to all players per team in the 2016-2017 season in dollars & http://www.basketballinsiders.com/ \\
\hline PSD17 & The standard deviation of the payroll for each team in dollars & Author Calculations \\
\hline
\end{tabular}


Many coaches state offense wins games, but defense wins championships. Defensive variables included in the sample are DREB17, STL17, and BLK17, which are also expected to be positively correlated with victories. DREB17 is the average number of times per game a defense successfully gains possession of the ball following an opposing team missed shot. STL17 is the times per game a defense takes the ball away from the opposing team. BLK17 is the average number of times a defense obstructs the ball from going into the hoop. Although, BlK17 does not insure taking possession of the ball, it generally helps reduces scoring by the opposing team.

A statistic many coaches monitor is the assist-to-turnover ratio. In this study, assists and turnovers are both included in the sample. Assists, AST17, is the number of times per game that a pass from one teammate to another results in a basket. Turnovers, TOV17, indicate the number of times per game that the ball is given to the other team via a foul or violation before a shot is taken.

$\mathrm{COACH} 17$, the head coach salary, is hypothesized to be positively correlated with WINS17. COACHEXP17, number of years as a head coach, as the related series. TOTFINE17 are total fines is assessed to each team during the season. The highest 2016-17 fine is \$3,282,364, assessed against New York Knicks Joakim Noah for violating the league drug policy. TOTFINE17 is expected to be inversely correlated with WINS17 because fines frequently include loss of playing time and likely impair team effectiveness. AGE17 and EXP17 are used to measure team intangibles such as greater insight and maturity that experienced and older players are expected to provide. To allow for negative returns, AGE17SQ is the average age of each team raised to the second power. An inverse correlation between WINS17 and the standard deviation of the team payrolls, PSD17, is hypothesized (Katayama and Nuch, 2011).

Because of the wide variety in rosters across the thirty teams in the NBA, a test for heteroscedasticity is necessary. The White (1980) test is used for this purpose. If the null hypothesis of homoscedasticity is rejected, the standard errors of the parameter estimates have to be re-calculated.

Table 2 reports summary statistics for all of the data included in the sample. There may be more competitive balance in the NBA than is commonly assumed. Coefficients of variation, not shown in Table 2 to avoid redundancy, are calculated as the ratios of the standard deviation to the mean for each of the variables included in the sample. Of the 19 variables listed in Table 2, 11 of them have coefficients of variation that are less than 0.100 . That implies that the data are tightly clustered about the respective means for these variables. In turn, that means that there are relatively little comparative differences among the teams for these variables.

The standard deviation for WINS17 is 11.88 . The maximum number of wins is 67 by the Golden State Warriors. The smallest number of victories is 20 by the Brooklyn Nets. Skewness for WINS17 is 0.252 , which is slightly asymmetric and right-skewed. Kurtosis, or the fourth moment, for WINS17 is 2.58 , which indicates the data are somewhat platykurtic relative to a normal distribution, and the coefficient of variation is 0.273 . 
Table 2. Summary Statistics

\begin{tabular}{|l|c|c|c|c|c|c|}
\hline Variable & Mean & Std. Deviation & Maximum & Minimum & Skewness & Kurtosis \\
\hline WINS17 & 41.0 & 11.2 & 67 & 20 & 0.252 & 2.580 \\
\hline PTS17 & 105.6 & 4.1 & 115 & 97.9 & 0.773 & 3.462 \\
\hline FGPCT17 & 45.7 & 1.4 & 49.5 & 43.5 & 0.610 & 3.095 \\
\hline PT3PCT17 & 35.7 & 1.8 & 39.1 & 32.7 & -0.015 & 1.949 \\
\hline FTPCT17 & 77.2 & 2.8 & 81.5 & 70.6 & -0.560 & 2.552 \\
\hline OREB17 & 10.1 & 1.2 & 12.2 & 7.9 & 0.197 & 1.899 \\
\hline DREB17 & 33.4 & 1.2 & 35.1 & 30.7 & -0.474 & 2.553 \\
\hline REB17 & 43.5 & 1.7 & 46.6 & 38.6 & -0.572 & 4.041 \\
\hline ASTAV17 & 22.6 & 2.2 & 30.4 & 18.5 & 1.323 & 6.309 \\
\hline TOV17 & 14.0 & 1.3 & 16.7 & 12.0 & 0.252 & 2.737 \\
\hline STL17 & 7.7 & 0.7 & 9.6 & 6.6 & 0.490 & 3.452 \\
\hline BLK17 & 4.7 & 0.7 & 6.8 & 3.7 & 0.776 & 3.611 \\
\hline COACH17 & $\$ 4,833,017$ & $\$ 2,486,781$ & $\$ 11,000,000$ & $\$ 2,000,000$ & 0.931 & 3.219 \\
\hline TOTFINE17 & $\$ 234,177$ & $\$ 591,875$ & $\$ 3,282,364$ & $\$ 12,000$ & 5.049 & 25.117 \\
\hline AGE17 & 26.5 & 1.3 & 29.90 & 24.6 & 1.128 & 3.461 \\
\hline AGE17SQ & 705.2 & 73.4 & 894.0 & 605.2 & 1.166 & 3.652 \\
\hline EXP17 & 4.7 & 1.4 & 8.50 & 2.1 & 1.235 & 4.266 \\
\hline PYRL17 & $\$ 98,443,474$ & $\$ 1,226,639$ & $\$ 127,254,579$ & $\$ 80,598,193$ & 0.383 & 2.802 \\
\hline PSD17 & $\$ 6,017,705$ & $\$ 1,376,395$ & $\$ 8,883,651$ & $\$ 3,385,426$ & -0.227 & 2.330 \\
\hline
\end{tabular}


The mean points scored in a game is 105.6. The standard deviation is 4.1. PTS17 ranges from a maximum of 115.9 for the Golden State Warriors to a minimum of 97.9 for the Dallas Mavericks. The distribution of PTS17 is righttailed with a skewness of 0.773 , and slightly leptokurtic with a kurtosis of 3.462 . The coefficient of variation for PTS17 is 0.039 .

The average field goal percentage is 45.7 , with a standard deviation of 1.37 , yielding a coefficient of variation is 0.03 . The FGPCT17 maximum is 49.5 by the Golden State Warriors, while the minimum is 43.5 by the Memphis Grizzles. FGPT17 has a third moment of 0.610 , indicating that this variable is skewed to the right. FGPCT17 is essentially mesokurtic with a fourth moment value of 3.095 .

The mean for the percentage of successful three-point shots is 35.7 with a standard deviation of 1.8. Observations for PT3PCT17 range from a maximum of 39.1 by the San Antonio Spurs to a minimum of 32.7 by the Oklahoma Thunder. The skewness is -0.015 , reflective of a largely symmetric distribution. The threepoint percentage data have thick tails with a kurtosis is 1.95 . In spite of that, the coefficient of variation value of 0.050 is not overly large.

The average free throw percentage for the season, FTPCT17, is 77.2 with a standard deviation of 2.8. The most accurate team on the free throw line is the Charlotte Hornets with a maximum of 81.5 percent. The least accurate team on the free throw line is the Miami Heat with a minimum of 70.6 percent. FTPCT17 is left skewed with a skewness of -0.560 and slightly platykurtic with a kurtosis of 2.552. Although the fourth moment is less than 3.0, the coefficient of variation is only 0.036 .

The average for offensive rebounds per game is 10.1 in Table 2. The standard deviation for OREB17 is 1.2 , with a maximum of 12.2 posted by the Chicago Bulls and minimum of 7.9 recorded by the Dallas Mavericks. The skewness coefficient is 0.197 , indicating that OREB17 is somewhat right-tailed. The kurtosis coefficient is 1.899 , implying thick tails, and the coefficient of variation is found to be 0.122 .

Defensive rebounds, DREB17, has a mean of 33.4 and a standard deviation of 1.2. Two teams, the Brooklyn Nets and the New Orleans Pelicans, charted the maximum season average of 35.1, while Dallas posted the league minimum tally of 30.7. The skewness for DREB17 is -0.474 , indicating that it tails off to the left. DREB17 is slightly platykurtic with a fourth moment of 2.553 . The coefficient of variation is 0.035 .

Total rebounds, REB17, has a mean of 43.5 and a standard deviation 1.7. The maximum season average is 46.6 by the Oklahoma Thunder, and the minimum season average is 38.6 by Dallas. The skewness is -0.572 , indicating that REB17 data are asymmetric and skew to the left. With a kurtosis value of 4.041, the data for REB17 are leptokurtic with thin tails relative to the Normal distribution. Given the latter, it is not surprising that the coefficient of variation for REB17 is 0.039 .

Teams average 22.6 assists per game with a standard deviation of 2.2 in Table 2. The Golden State Warriors recorded the maximum season average of 30.4. The Toronto Raptors generated the minimum season average at 18.5. AST17 skews to the right and has a third moment of 1.323 . These data are 
highly leptokurtic with a fourth moment estimate of 6.309. The coefficient of variation for AST17 is 0.098 .

The mean for turnovers is 14.0 with a standard deviation of 1.3. The maximum value for TOV17 is 16.7 by the Philadelphia 76ers, while the 201617 season minimum is 12.0 by the Charlotte Hornets. The skewness for TOV17 is 0.252 . With a kurtosis of 2.737 , TOV17 has somewhat thick tails, but the coefficient of variation is still only 0.091 .

The mean for steals per game is 7.7 with a standard deviation of 0.7 and a coefficient of variation of 0.085 . Golden State achieved the STL17 maximum of 9.6, while the Cleveland Cavaliers ranked at the bottom of the NBA with only 6.6 steals per game. The skewness for STL17is 0.490 and the kurtosis is 3.452 .

The season average for blocked shots is 4.7 per game with a standard deviation of 0.7 , yielding a coefficient of variation of 0.150 . The maximum for BLK17 is 6.8 by Golden State. Dallas trailed the entire league with an average of 3.7 shot blocks per game. The third moment for BLK17 is 0.776 and the fourth moment is 3.611, indicating some asymmetry, but a relatively tight distribution about the mean for this variable.

The average 2016-17 salary for a coach in the NBA is $\$ 4,833,017$ with a standard deviation of $\$ 2,486,781$. The maximum salary is $\$ 11,000,000$, paid to Gregg Popovich of the San Antonio Spurs. The minimum is $\$ 2,000,000$, paid to Mike Budenhoizer of the Atlanta Hawks, Steve Clifford of the Charlotte Hornets, Michael Malone of the Denver Nuggets, and to Brett Brown of the Philadelphia 76ers. The skewness statistic is 0.931, indicating that these data, slightly, tail to the right. The kurtosis for $\mathrm{COACH} 17$ is 3.219 , while the coefficient of variation is 0.515 .

The 2016-17 average fines per team is $\$ 234,177$ with a standard deviation of $\$ 591,875$. Such wide dispersion among these data causes the coefficient of variation to exceed 2.5 , easily the largest value for this statistic among any of the variables listed in Table 2. The maximum for TOTFINE17 is the $\$ 3,282,364$ assessed against the New York Knicks. At the other end of this spectrum is the minimum, and minimal, $\$ 12,000$ total paid by the apparently well-disciplined San Antonio Spurs. Because these data are strongly right-skewed, the third moment is 5.049. The fourth moment of TOTFINE17 is 25.117, indicating that these data are exceptionally leptokurtic, but with a very high coefficient of variation as already noted.

The mean for AGE17 is 26.5 years with a compact second moment of only 1.3. The Cleveland Cavaliers hold the 2016-17 maximum average age at 29.9 . The Portland Trail Blazers have the minimum average age of 24.6 in Table 2. The skewness for AGE17 is 1.128 indicating the distribution is positively skewed, with a fourth moment of 3.461 indicating the data are slightly leptokurtic, and a coefficient of variation of 0.051 . To allow for diminishing and, eventually, negative returns to age, AGE17SQ is also included in the sample.

The mean for years spent in the NBA, EXP17, is 4.7 with a standard deviation of 1.4. Given the collective age of the roster for the Cleveland Cavaliers, it is no surprise that maximum value of 8.5 years is associated with that team. Not 
surprisingly, the minimum amount of league experience is posted by Portland. The third moment for EXP17 is 1.235, which indicates that the distribution skews to the right. The kurtosis is 4.266, indicating that these data are leptokurtic.

The first moment for PYRL17 is $\$ 98,443,474$ with a standard deviation of $\$ 11,226,639$. The team with the highest payroll of $\$ 127,254,579$ is the Golden State Warriors, the champions of the 2016-2017 season. While Utah has the lowest payroll of $\$ 80,598,193$ in Table 2, the Jazz did not finish in last place for the season. The skewness coefficient is 0.383 , and the kurtosis is 2.802 , indicating that the PRYL17 data basically follow a normal distribution.

The mean for team payroll standard deviation in Table 2 is $\$ 6,017,705$ with a standard deviation of $\$ 1,376,395$. Cleveland, the 2016-17 home of Lebron James, has the maximum PSD17 at $\$ 8,883,652$. Philadelphia has the minimum of $\$ 3,385,426$. The skewness is -0.277 , indicating substantial symmetry for PSD17 observations. The fourth moment is 2.330 , indicating somewhat platykurtic thick tails. Somewhat reflective of the latter statistic, the coefficient of variation is 0.229 .

The specification shown in Equation (1) is used to model wins during the NBA 2016-17 regular season:

$$
\begin{aligned}
\operatorname{LnWINS} 17= & \beta_{0}+\beta_{1} \operatorname{LnPTS} 17+\beta_{2} \operatorname{LnFGPCT} 17+\beta_{3} \operatorname{LnPT} 3 \text { PCT17 }+\beta_{4} \operatorname{LnFTPCT} 17 \\
& +\beta_{5} \operatorname{Ln} 0 \text { REB17 }+\beta_{6} \operatorname{LnDREB} 17+\beta_{7} \operatorname{LnREB} 17+\beta_{8} \operatorname{LnASTAV} 17 \\
& +\beta_{9} \operatorname{LnT0V17}+\beta_{10} \operatorname{LnSTL} 17+\beta_{11} \operatorname{LnBLK} 17+\beta_{12} \operatorname{LnC0ACH} 17 \\
& +\beta_{13} \operatorname{LnT0TFINE} 17+\beta_{14} \operatorname{LnAGE} 17+\beta_{15} \operatorname{LnEXP17}+\beta_{16} \operatorname{LnPYRL} 17 \\
& +\beta_{17} \operatorname{LnPSD} 17+\varepsilon_{t}
\end{aligned}
$$

Equation (1) specifies WINS17 as a function of all of the variables from Table 1 and a stochastic error term. The hypothesized parameter signs for most of the parameters are positive. The exceptions are the coefficients for TOV17, TOTFINE17, and PSD17 which are expected to be negative.

\section{Empirical Analysis}

The Indiana Pacers do not publish coaching salaries. Regression analysis and in-sample simulation are used to estimate the missing data point for that variable (Friedman, 1962). The number of years of NBA plus college head coaching experience is used as the explanatory variable in Equation (2). Estimation results for Equation (2) are summarized in Table 3. Inputting the head 12 years of coaching experience for Nate McMillan yields \$5,426,275 as the 2016-17 salary estimate for the Indiana Pacers.

$$
\mathrm{COACH} 17=\beta_{0}+\beta_{1} \mathrm{COACHEXP} 17+\varepsilon_{t}
$$


Table 3. Head Coach Salary Regression Results

\begin{tabular}{|c|c|c|c|}
\hline Variable & Coefficient & t-Statistic & Probability \\
\hline Constant & $2,938,879$ & 4.716 & 0.001 \\
\hline COACHEXP17 & 207,283 & 3.827 & 0.001 \\
\hline R-squared & 0.352 & Mean Dep. Var. & $4,833,017$ \\
\hline Adjusted R-Sq. & 0.328 & S.D. Dep Var. & $2,486,781$ \\
\hline Std. Err. Reg. & $2,038,988$ & Akaike Info Crit. & 31.960 \\
\hline Sum. Sq. Resid & $1.12 \mathrm{E}+14$ & Schwart Info Crit. & 32.055 \\
\hline Log-likelihood & -461.424 & Hannan-Quinn Crit. & 31.990 \\
\hline F-statistic & 14.649 & Prob(F-statistic) & 0.001 \\
\hline
\end{tabular}

Table 4. Heteroscedasticity Corrected Regression Results Summary for Regular Season Wins

\begin{tabular}{|c|c|c|c|}
\hline Variable & Coefficient & t-Statistic & Probability \\
\hline C & 18.281 & 0.998 & 0.338 \\
\hline LNPTS17 & -0.658 & -0.437 & 0.670 \\
\hline LNFGPCT17 & 3.223 & 1.188 & 0.258 \\
\hline LNPT3PCT17 & 2.051 & 1.475 & 0.166 \\
\hline LNFTPCT17 & -0.096 & -0.087 & 0.932 \\
\hline LNOREB17 & 11.890 & 1.659 & 0.123 \\
\hline LNDREB17 & 40.956 & 1.744 & 0.107 \\
\hline LNASTAV17 & 0.107 & 0.218 & 0.831 \\
\hline LNTOV17 & -0.826 & -1.368 & 0.196 \\
\hline LNSTL17 & 0.777 & 1.576 & 0.141 \\
\hline LNBLK17 & -0.232 & -0.856 & 0.409 \\
\hline LNCOACH17 & -0.022 & -0.306 & 0.765 \\
\hline LNTOTFINE17 & -0.019 & -0.572 & 0.578 \\
\hline LNAGE17 & 0.237 & 0.152 & 0.881 \\
\hline LNEXP17 & -0.173 & -0.578 & 0.574 \\
\hline LNPYRL17 & -1.307 & -2.777 & 0.017 \\
\hline LNPSD17 & 0.936 & 2.945 & 0.012 \\
\hline R-squared & 0.891 & Mean Dep. Var. & 3.676 \\
\hline Adjusted R-Sq. & 0.736 & S.D. Dep Var. & 0.285 \\
\hline Std. Err. Reg. & 0.147 & Sum. Sq. Resid. & 0.258 \\
\hline F-statistic & 5.748 & Prob. (F-statistic) & 0.002 \\
\hline Log-likelihood & 28.779 & & \\
\hline
\end{tabular}

\section{LnWINS17 $=\beta_{0}+\beta_{1} \operatorname{LnFGPCT17}+\beta_{2} \operatorname{LnFTPCT} 17+\beta_{3} \operatorname{Ln} 0$ REB17 $+\beta_{4} \operatorname{LnDREB} 17$ $+\beta_{5} \operatorname{LnT0V} 17+\beta_{6} \operatorname{LnCOACH} 17+\beta_{7} \operatorname{LnPYRL} 17+\beta_{8} \operatorname{LnPSD} 17+\varepsilon_{t}$}


Estimation results for Equation (1) are reported in Table 4. This initial equation includes sixteen explanatory variables. Very few of the computed t-statistics in Table 4 satisfy the 5-percent significance criterion and several coefficients exhibit illogical arithmetic signs. Part of the reason for the parametric insignificance is the small number of sample observations. Multicollinearity may also be present in the sample. The White (1980) test rejects the null hypothesis of homoscedasticity. Some of the parameter signs also run counter to what is hypothesized above.

Given the outcomes shown in Table 4, an alternative specification with fewer explanatory variables is employed, next. Estimation results for Equation (3) are summarized in Table 5. Eight regressors are included in this second specification. Three of the eight coefficients have computed t-statistics that satisfy the 5-percent significance criterion. Similar to the results of Peach et. al. (2016) and Fullerton and Peach (2016), the signs for most of the parameter estimates are as hypothesized. To correct for heteroscedasticity, the White (1980) method is employed.

The parameter for field goal percentage is positive with a 5.812 magnitude that satisfies the 5-percent significance criterion. A one-unit increase in FGPCT17 will lead to a 5.8 percent increase in regular season victories. Because wins are determined by scoring the most points, this result is expected. As shown in Figure 1 , victories are positively correlated with field goal percentage and that correlation is easily discernible.

Table 5. Alternative Specification Results Summary for Regular Season Wins

\begin{tabular}{|c|c|c|c|}
\hline Variable & Coefficient & t-Statistic & Probability \\
\hline C & -10.817 & -1.205 & 0.242 \\
\hline LNFGPCT17 & 5.812 & 5.377 & 0.000 \\
\hline LNFTPCT17 & 0.099 & 0.127 & 0.900 \\
\hline LNOREB17 & -0.191 & -0.650 & 0.523 \\
\hline LNDREB17 & 0.305 & 0.296 & 0.770 \\
\hline LNTOV17 & -0.524 & -1.106 & 0.281 \\
\hline LNCOACH17 & -0.076 & -0.869 & 0.395 \\
\hline LNPYRL17 & -1.197 & -2.599 & 0.016 \\
\hline LNPSD17 & 1.013 & 4.612 & 0.000 \\
\hline R-squared & 0.761 & Mean Dep. Var. & 3.676 \\
\hline Adjusted R-Sq. & 0.670 & S.D. Dep Var. & 0.285 \\
\hline Std. Err. Reg. & 0.164 & Sum. Sq. Resid. & 0.563 \\
\hline F-statistic & 8.369 & Prob. (F-statistic) & 0.000 \\
\hline Log-likelihood & 17.068 & & \\
\hline
\end{tabular}


Figure 1. 2016-17 NBA Regular Season Wins vs. Field Goal Percentage per Game

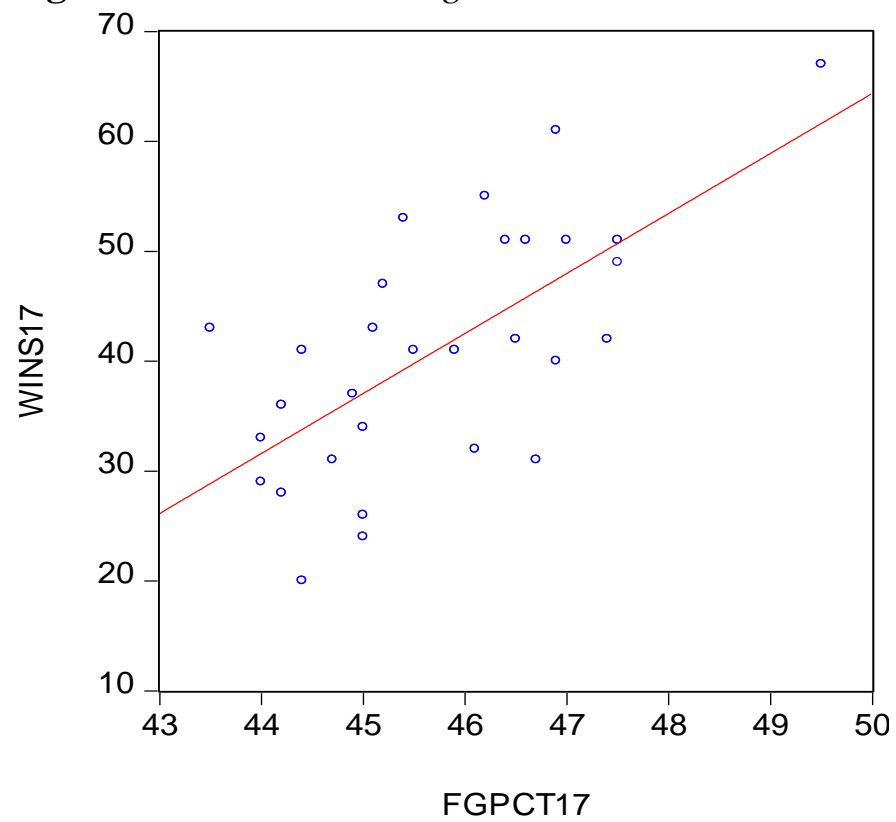

The free throw percentage coefficient is positive, but does not satisfy the 5-percent significance criterion. Somewhat surprisingly, the parameter estimate indicates that this variable has a low impact on wins. However, free throws usually account for a small percentage of total points. As shown in Figure 2, wins and FTPCT17 appear weakly correlated at best. Both of the signs for the parameter estimates of natural log of field goal percentage and natural log of free throw percentage align with those of the McGoldrick and Voeks (2005) study.

Figure 2. 2016-17 NBA Regular Season Wins vs. Average Free Throw Percentage per Game

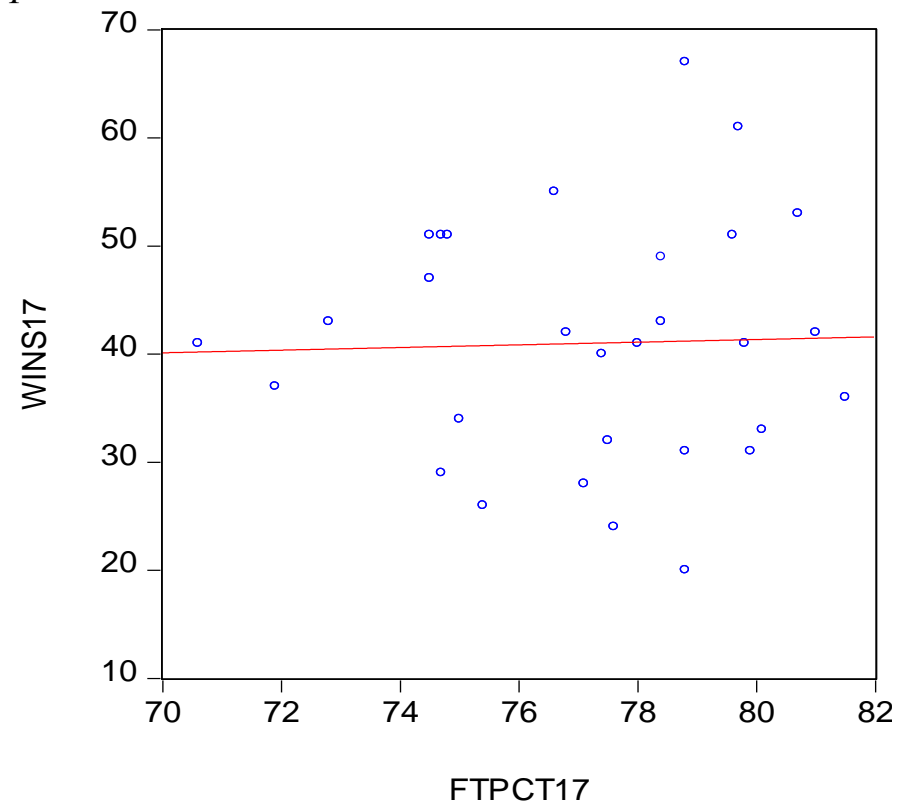


The coefficient for offensive rebounding does not surpass the 5-percent significance threshold. The negative sign for this coefficient is counterintuitive. This may be because the data for this variable are grouped together very tightly and do not allow any teams to gain very much of an advantage over the others. As shown in Figure 3, regular season wins are negatively correlated with OREB17, but the relationship is not very strong. An alternative possibility is that offensive rebounds result from missed shots. Consequently, greater numbers of offensive rebounds reflect shooting futility and will, logically, be associated with fewer victories. However, that is not the null hypothesis stated above and additional research is required to further examine that possibility.

Figure 3. 2016-17 NBA Wins vs. Average Offensive Rebounds per Game

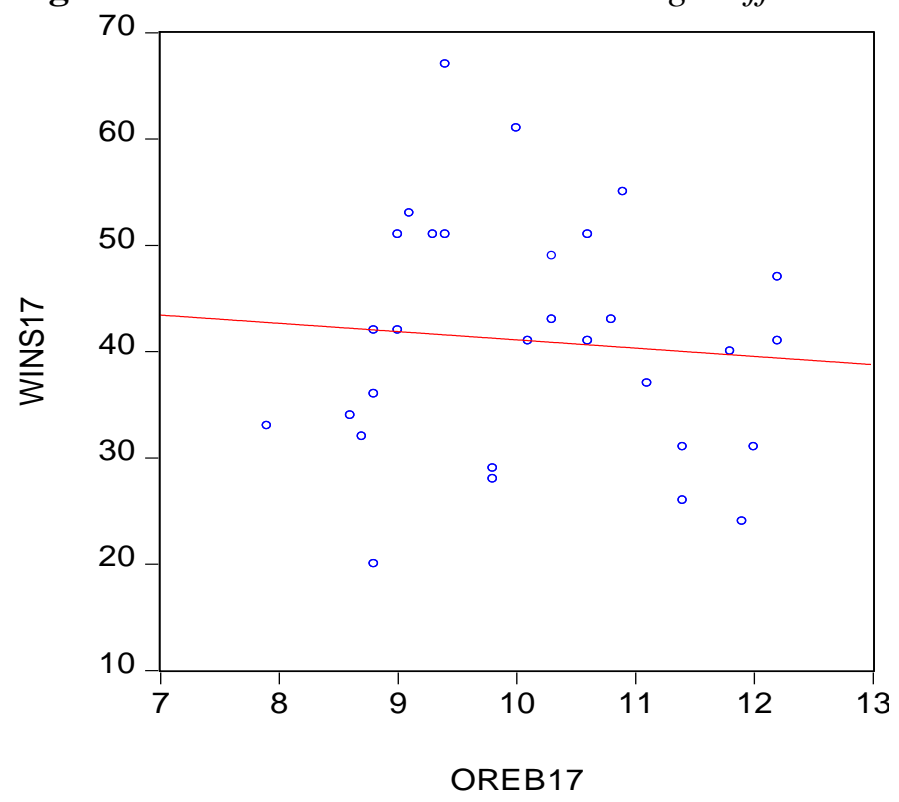

Figure 4. 2016-2017 NBA Regular Season Wins vs. Average Defensive Rebounds per Game

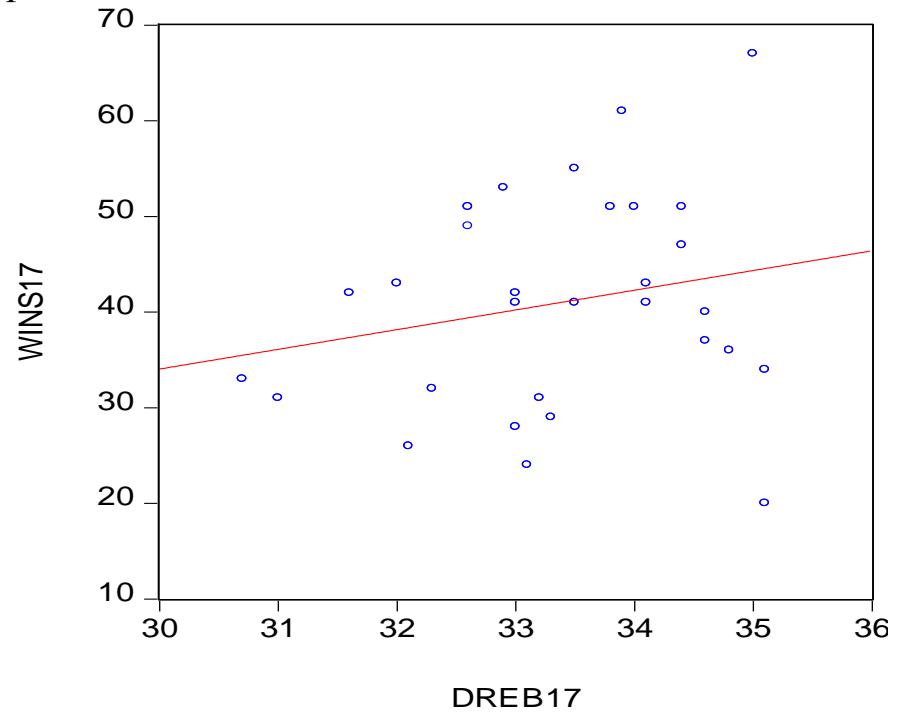


The defensive rebounding parameter is positive with a magnitude of 0.305 , but does not satisfy the standard significance criterion. The insignificance is surprising, as defensive rebounds remove possession from the opposing team and reduce opportunities to attempt shots. As shown in Figure 4, victories are positively correlated with DREB17. Estimates of the marginal effects associated with Equation (3) appear in Table 6. The marginal effect for the variable defensive rebounding is 0.374 . Eleven additional defensive rebounds per game increase total wins by four.

The estimated parameter for turnovers is negative with a magnitude of -0.524 . That suggests that a ten percent increase in turnovers will result in a 5.2 percent decrease in wins. Even though it does not meet the 5-percent significance criterion, the TOV17 coefficient is negative as hypothesized. Reducing turnovers allows a team more opportunities to score. It is fairly easy to see in Figure 5 that victories are negatively correlated with turnovers.

Figure 5. 2016-17 NBA Regular Season Wins vs. Average Turnovers per Game

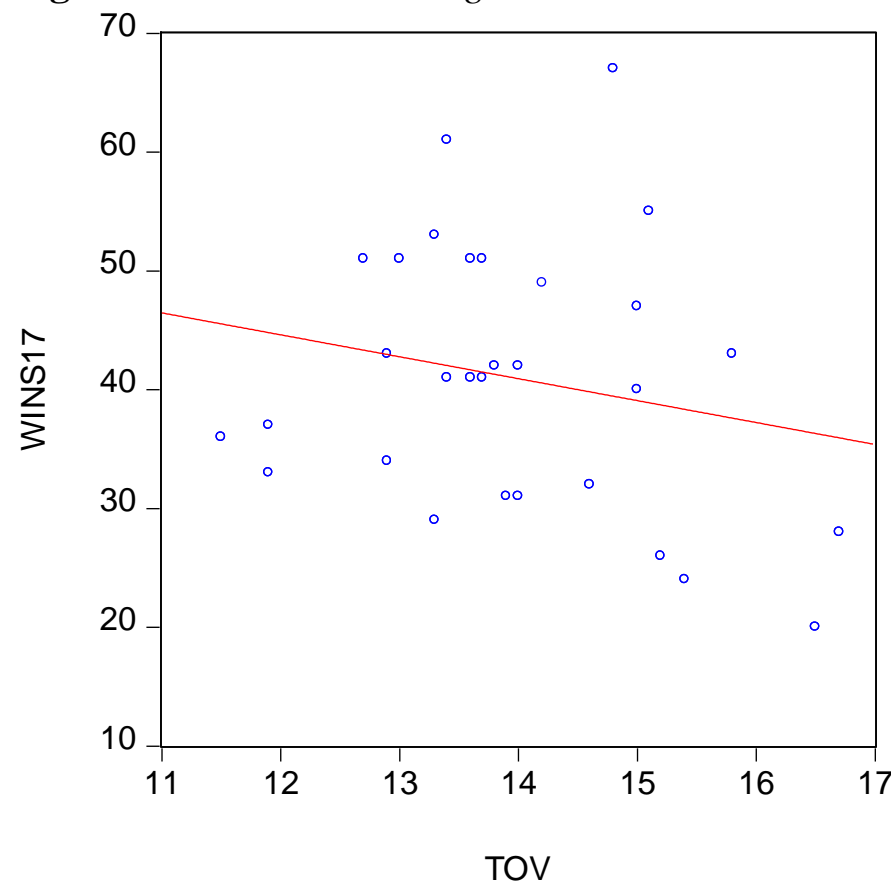

The coefficient for coach salaries does not satisfy the standard significance criterion. The parameter is very close to zero and suggests that victories are not affected by coaching compensation. The implication is that spending more on head coaches will not generate additional wins. As shown in Figure 6, wins do appear to be positively correlated with $\mathrm{COACH} 17$, but with a fairly large degree of variability. 
Figure 6. 2016-17 NBA Regular Season Wins vs. Coaching Salaries

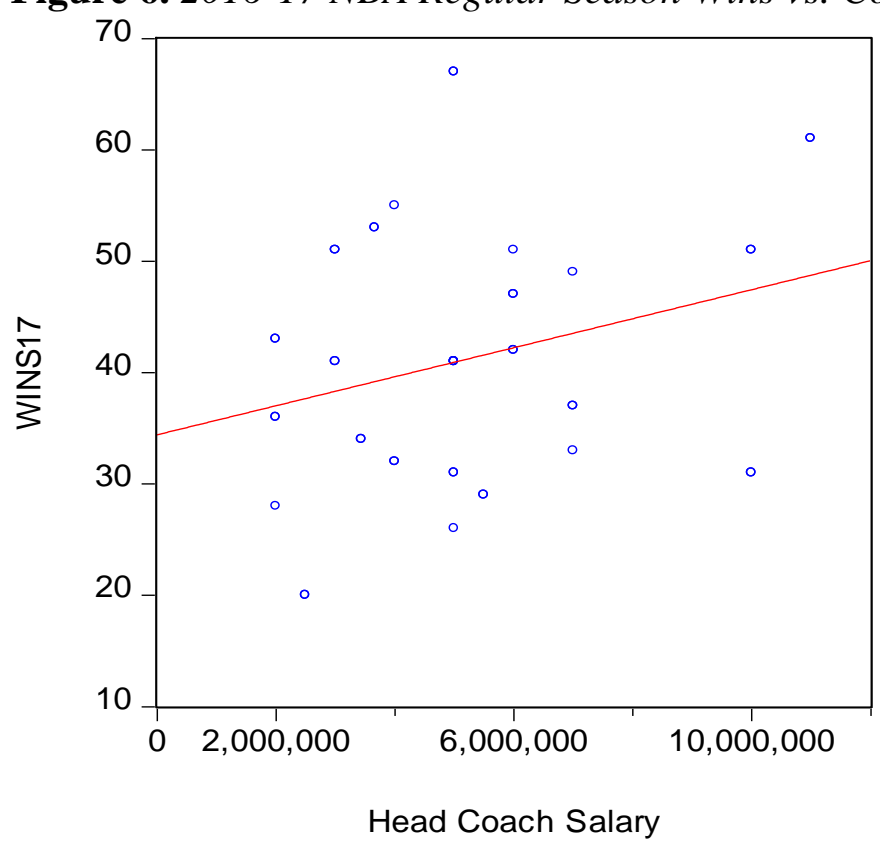

The parameter estimate for the natural log of payroll is statistically significant, but is inversely correlated with regular season wins. That runs counter to what is hypothesized. According to the result shown in Table 5, a one percent increase in payroll will reduce wins by 1.1 percent. However, the marginal effect reported in Table 6 is 0.0. Further shrouding this issue in mystery, a casual perusal of Figure 7 suggests that victories are positively correlated with PYRL17. Collectively, the evidence disparities indicate that that human capital analysis in the NBA is less straightforward than what has been reported for other spectator sports such as MLB (Fullerton and Peach, 2017) or the NFL (Fullerton et al., 2017).

Figure 7. 2016-17 NBA Regular Season Wins vs. Team Payrolls

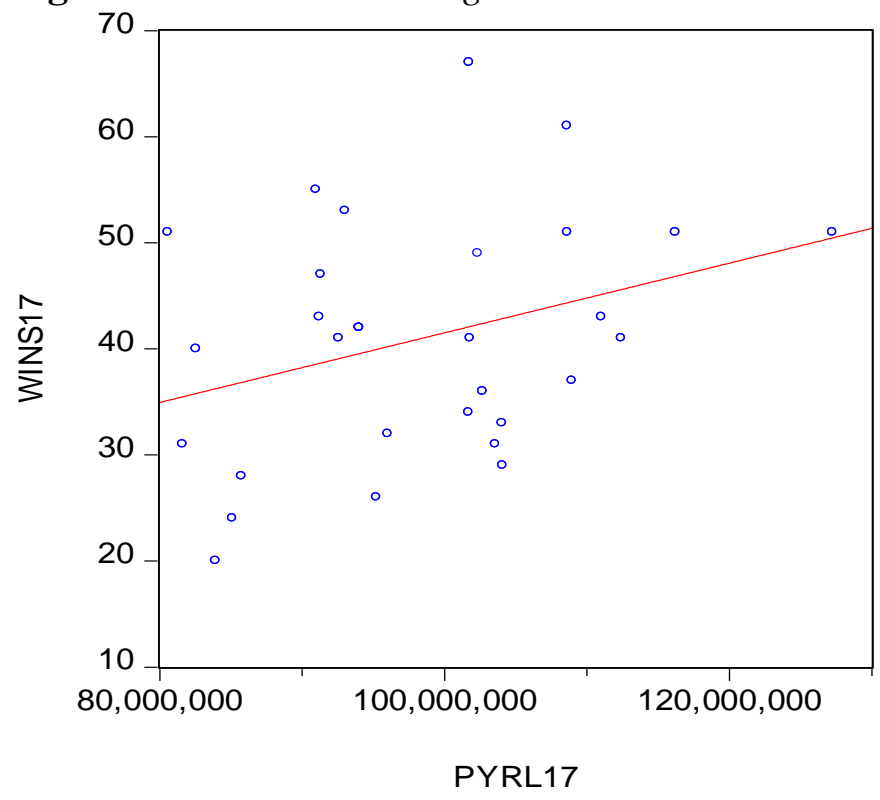


The natural $\log$ of the standard deviation of the payroll for each team is included in the sample to allow for personnel infighting and discord that may result from paying a large portion of the salary cap to a small group of players. The estimated slope coefficient for this regressor in Table 5 is statistically significant and positive. That is opposite of what Katayama and Nuch (2011) suggest. The result for 2016-17 suggests that it is better to pay a small number of highly effective players most of the team salary cap. As can be discerned in Figure 8 , victories seem to be positively correlated with PSD17.

Figure 8. 2016-17 NBA Regular Season Wins vs. Team Payroll Standard Deviations

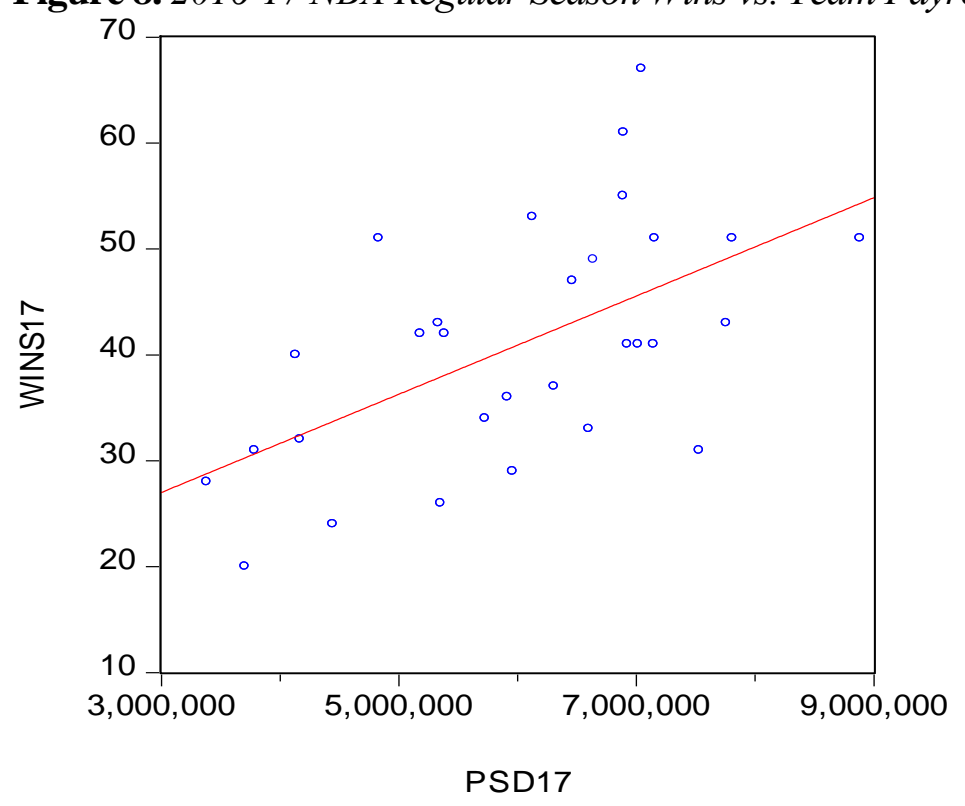

Table 6. Independent Variable Marginal Effects Table

\begin{tabular}{|c|c|c|c|}
\hline \multicolumn{4}{|c|}{ Independent Variable Marginal Effects } \\
\hline Variable & Coefficient & Mean & Marginal Effect \\
\hline WINS17 & N/A & 41.0 & N/A \\
\hline FGPCT17 & 5.812 & 45.7 & 5.214 \\
\hline FTPCT17 & 0.099 & 77.2 & 0.053 \\
\hline OREB17 & -0.191 & 10.1 & -0.775 \\
\hline DREB17 & 0.305 & 33.4 & 0.374 \\
\hline TOV17 & -0.524 & 14.0 & -1.535 \\
\hline COACH17 & -0.076 & $\$ 4,833,017$ & 0.000 \\
\hline PYRL17 & -1.197 & $\$ 98,443,474$ & 0.000 \\
\hline PSD17 & 1.013 & $\$ 6,017,705$ & 0.000 \\
\hline
\end{tabular}

Note: Marginal effects are calculated as $\frac{d W I N S 17}{d x}=\hat{\beta}_{x} * \frac{\overline{W I N S 17}}{\bar{X}}$ for each explanatory variable included in Table 5.

The vast majority of the parameter estimate signs for Equation (3) do not match what is hypothesized above. These outcomes are distinct from the patterns found for MLB (Fullerton and Peach, 2017) or the NFL (Fullerton et al., 2017). One factor behind this departure from the other major professional spectator sports 
in the United States may be over-valued contracts. During the 2016 off-season teams spent record amounts on post players. The following player salaries total more than $\$ 365$ million, which is approximately 4 times the $\$ 94$ million salary cap allotted to each team: Los Angeles Laker, Timofey Mozgov; New York Knicks, Joakim Noah; Washington Wizards, Ian Mahimi; Portland Trailblazers, Meyers Leonard; Orlando Magic, Bismack Biyomobo and Charlotte Hornets, Miles Plumlee. These players are all post players whose primary job is to rebound. Those players tend to have low field goal shooting percentages.

It may not be feasible to successfully model NBA regular seasons in a manner similar to MLB or the NFL. The numbers of players on the field in those sports mandates more teamwork among players. (Katayama and Nuch, 2011). In the NBA, one player can change the outcome of the game. For example, the Reggie Miller eight points in nine seconds closed out a game for a playoff victory. During the nine second stretch, Miller, with little help from his teammates, was responsible for a steal, defensive rebound, two successful three-point shots, and two successful free throws (Callahan, 1995). Actions of this magnitude would be difficult to duplicate in either the MLB or the NFL.

\section{Conclusion}

This study examines the on-court performance of the thirty NBA teams during the 2016-17 NBA basketball season. To date, there have been relatively few studies that use regular season cross sectional data to examine team performances. In contrast to recent studies for the NFL and MLB, the empirical results for this effort are largely inconclusive. One key departure is the parameter sign for the human capital payroll variable, which is both negative and statistically significant

The results suggest that players with high field goal percentages will, as hypothesized, help teams win. Other on court performance variables are not found to be reliably linked to team successes. While contrary to what is hypothesized for it, the outcome for payroll dispersion suggests that NBA teams should consider larger salary gaps and allow for one-to-three players to command the better parts of team payrolls.

Because of the small number of observations, there is an obvious pathway for further inquiry. Although coaching salaries for the NBA are not all published, coaching salaries for the NCAA are public record. Inclusion of all coaches on staff across all teams may generate additional insights. Replication of this study employing all 437 NCAA teams may also combat against multicollinearity. There is likely a positive correlation between coaching salaries and wins in the NCAA. Support for the other hypotheses discussed above may also prove less elusive in a study of the NCAA regular season wins.

\section{Acknowledgements}

Financial support for this research was provided by El Paso Water, City of El Paso Office of Management \& Budget, National Science Foundation Grant DRL- 
1740695, TFCU, the UTEP Center for the Study of Western Hemispheric Trade, and the Hunt Institute for Global Competitiveness at UTEP. Helpful comments and suggestions were provided by Joshua Fan and an anonymous referee. Econometric research assistance was provided by Aaron Nazarian, Steve Fullerton, and Sergio Olivas.

\section{References}

Berri, D. (1999). "Who is 'Most Valuable'? Measuring the Player's Production of Wins in the National Basketball Association," Managerial and Decision Economics 20(8), 411-427.

Berri, D. and Eschker E. (2005). "When it Counts? The Myth of the Prime Time Performer in Professional Basketball," Journal of Economic Issues 39(3), 798-807.

Callahan, G. (1995). "Floored! With Two Three-Point Thunderbolts, the Pacers' Reggie Miller Shocked the Knicks," Sports Illustrated 82(19), 26-29.

Friedman, M. (1962). "The Interpolation of Time Series by Related Series," Journal of the American Statistical Association 57(300), 729-757.

Fullerton, S.L., Holcomb, J.H., and Fullerton, Jr., T.M. (2017). “Any Given Season?” Journal of Economics \& Political Economy 4(3), 238-246.

Fullerton, S.L., Fullerton, Jr., T.M., and Walke, A.G. (2014). "An Econometric Analysis of the 2013 Major League Baseball Season," Research in Business \& Economics Journal 9, 115-120.

Fullerton, Jr., T.M. and Peach, J.T. (2016). "Major League Baseball 2015, What a Difference a Year Makes," Applied Economics Letters 23(18), 1289-1293.

Fullerton, Jr., T.M. and Peach, J.T. (2017). "Slingshots, Leather, Lumber and the 2016 Season in Major League Baseball," Journal of Sports Economics \& Management 7(3), 130-142.

Jewell, T. and Molina, D. J. (2004). "Productive Efficiency and Salary Distribution: The Case of US Major League Baseball," Scottish Journal of Political Economy 51(1), 127-142.

Katayama, H. and Nuch, H. (2011). "A Game-Level Analysis of Salary Dispersion and Team Performance in the National Basketball Association," Applied Economics 43(10), 1193-1207.

McGoldrick, K. and Voeks, L. (2005). "We Got Game! An Analysis of Win/Loss Probability and Efficiency Differences between the NBA and WNBA," Journal of Sports Economics 6(1) 5-23.

Peach, T., Fullerton, S.L., and Fullerton Jr., T.M. (2016). "An Empirical Analysis of the 2014 Major League Baseball Season," Applied Economics Letters 23(2), 138-141.

Wallace, S., Caudill, S.B., and Mixon Jr, F.G. (2013). "Homo Certus in Professional Basketball? Empirical Evidence from the 2011 NBA Playoffs," Applied Economics Letters 20(7), 642-648.

White, H. (1980). "A Heteroskedasticity-Consistent Covariance Matrix Estimator and a Direct Test for Heteroskedasticity," Econometrica 48, 817-838.

Zimmer, T. and Kuethe, T. (2009). "Testing for Bias and Manipulation in the National Basketball Association Playoffs," Journal of Quantitative Analysis in Sports 5(3), 113. 
Vol. 7, No. 2 Fullerton et al.: Empirical Mysteries of the 2016-17 NBA Regular Season

\section{Data Appendix}

Table 1.

\begin{tabular}{|l|c|c|c|c|c|c|}
\hline Team & GP & WINS17 & PTS17 & FGPCT17 & PT3PCT17 & FTPCT17 \\
\hline Atlanta Hawks & 82 & 43 & 103.2 & 45.1 & 34.1 & 72.8 \\
\hline Boston Celtics & 82 & 53 & 108 & 45.4 & 35.9 & 80.7 \\
\hline Brooklyn Nets & 82 & 20 & 105.8 & 44.4 & 33.8 & 78.8 \\
\hline Charlotte Hornets & 82 & 36 & 104.9 & 44.2 & 35.1 & 81.5 \\
\hline Chicago Bulls & 82 & 41 & 102.9 & 44.4 & 34 & 79.8 \\
\hline Cleveland Cavaliers & 82 & 51 & 110.3 & 47 & 38.4 & 74.8 \\
\hline Dallas Mavericks & 82 & 33 & 97.9 & 44 & 35.5 & 80.1 \\
\hline Denver Nuggets & 82 & 40 & 111.7 & 46.9 & 36.8 & 77.4 \\
\hline Detroit Pistons & 82 & 37 & 101.3 & 44.9 & 33 & 71.9 \\
\hline Golden State Warriors & 82 & 67 & 115.9 & 49.5 & 38.3 & 78.8 \\
\hline Houston Rockets & 82 & 55 & 115.3 & 46.2 & 35.7 & 76.6 \\
\hline Indiana Pacers & 82 & 42 & 105.1 & 46.5 & 37.6 & 81 \\
\hline LA Clippers & 82 & 51 & 108.7 & 47.5 & 37.5 & 74.5 \\
\hline Los Angeles Lakers & 82 & 26 & 104.6 & 45 & 34.6 & 75.4 \\
\hline Memphis Grizzlies & 82 & 43 & 100.5 & 43.5 & 35.4 & 78.4 \\
\hline Miami Heat & 82 & 41 & 103.2 & 45.5 & 36.5 & 70.6 \\
\hline Milwaukee Bucks & 82 & 42 & 103.6 & 47.4 & 37 & 76.8 \\
\hline Minnesota Timberwolves & 82 & 31 & 105.6 & 46.7 & 34.9 & 79.9 \\
\hline New Orleans Pelicans & 82 & 34 & 104.3 & 45 & 35 & 75 \\
\hline New York Knicks & 82 & 31 & 104.3 & 44.7 & 34.8 & 78.8 \\
\hline Oklahoma City Thunder & 82 & 47 & 106.6 & 45.2 & 32.7 & 74.5 \\
\hline Orlando Magic & 82 & 29 & 101.1 & 44 & 32.8 & 74.7 \\
\hline Philadelphia 76ers & 82 & 28 & 102.4 & 44.2 & 34 & 77.1 \\
\hline Phoenix Suns & 82 & 24 & 107.7 & 45 & 33.2 & 77.6 \\
\hline Portland Trail Blazers & 82 & 41 & 107.9 & 45.9 & 37.5 & 78 \\
\hline Sacramento Kings & 82 & 32 & 102.8 & 46.1 & 37.6 & 77.5 \\
\hline San Antonio Spurs & 82 & 61 & 105.3 & 46.9 & 39.1 & 79.7 \\
\hline Toronto Raptors & 82 & 51 & 106.9 & 46.4 & 36.3 & 79.6 \\
\hline Utah Jazz & 82 & 51 & 100.7 & 46.6 & 37.2 & 74.7 \\
\hline Washington Wizards & 82 & 49 & 109.2 & 47.5 & 37.2 & 78.4 \\
\hline & & & & & & \\
\hline
\end{tabular}

Notes:

Only variables with the 17 suffix are used in the empirical analysis.

GP stands for regular season games played.

WINS17 is the number of 2016-17 regular season games won by each team.

PTS17 is the 2016-17 regular season points per game average for each team.

FGPCT17 is the 2016-17 regular season shooting percentage within the 3-point arc by each team, not including free throws.

PT3PCT17 is the 2016-17 regular season shooting percentage from beyond the 3-point arc for each team.

FTPCT17 is the 2016-17 regular season free throw percentage for each team. 
Table 2.

\begin{tabular}{|c|c|c|c|c|c|c|}
\hline Team & OREB17 & DREB17 & ASTAV17 & TOV17 & STL17 & BLK17 \\
\hline Atlanta Hawks & 10.3 & 34.1 & 23.6 & 15.8 & 8.2 & 4.8 \\
\hline Boston Celtics & 9.1 & 32.9 & 25.2 & 13.3 & 7.5 & 4.1 \\
\hline Brooklyn Nets & 8.8 & 35.1 & 21.4 & 16.5 & 7.2 & 4.7 \\
\hline Charlotte Hornets & 8.8 & 34.8 & 23.1 & 11.5 & 7 & 4.8 \\
\hline Chicago Bulls & 12.2 & 34.1 & 22.6 & 13.6 & 7.8 & 4.8 \\
\hline Cleveland Cavaliers & 9.3 & 34.4 & 22.7 & 13.7 & 6.6 & 4 \\
\hline Dallas Mavericks & 7.9 & 30.7 & 20.8 & 11.9 & 7.5 & 3.7 \\
\hline Denver Nuggets & 11.8 & 34.6 & 25.3 & 15 & 6.9 & 3.9 \\
\hline Detroit Pistons & 11.1 & 34.6 & 21.1 & 11.9 & 7 & 3.8 \\
\hline Golden State Warriors & 9.4 & 35 & 30.4 & 14.8 & 9.6 & 6.8 \\
\hline Houston Rockets & 10.9 & 33.5 & 25.2 & 15.1 & 8.2 & 4.3 \\
\hline Indiana Pacers & 9 & 33 & 22.5 & 13.8 & 8.2 & 5 \\
\hline LA Clippers & 9.0 & 34.0 & 22.5 & 13 & 7.5 & 4.2 \\
\hline Los Angeles Lakers & 11.4 & 32.1 & 20.9 & 15.2 & 8.2 & 3.9 \\
\hline Memphis Grizzlies & 10.8 & 32.0 & 21.3 & 12.9 & 8 & 4.2 \\
\hline Miami Heat & 10.6 & 33.0 & 21.2 & 13.4 & 7.2 & 5.7 \\
\hline Milwaukee Bucks & 8.8 & 31.6 & 24.2 & 14 & 8.1 & 5.3 \\
\hline Minnesota Timberwolves & 11.4 & 31.0 & 23.7 & 14 & 8 & 4.5 \\
\hline New Orleans Pelicans & 8.6 & 35.1 & 22.8 & 12.9 & 7.8 & 5.5 \\
\hline New York Knicks & 12.0 & 33.2 & 21.8 & 13.9 & 7.1 & 5.5 \\
\hline Oklahoma City Thunder & 12.2 & 34.4 & 21.0 & 15 & 7.9 & 5 \\
\hline Orlando Magic & 9.8 & 33.3 & 22.2 & 13.3 & 7.1 & 4.8 \\
\hline Philadelphia 76ers & 9.8 & 33.0 & 23.8 & 16.7 & 8.4 & 5.1 \\
\hline Phoenix Suns & 11.9 & 33.1 & 19.6 & 15.4 & 8.2 & 4.9 \\
\hline Portland Trail Blazers & 10.1 & 33.5 & 21.1 & 13.7 & 7 & 5 \\
\hline Sacramento Kings & 8.7 & 32.3 & 22.5 & 14.6 & 7.6 & 4 \\
\hline San Antonio Spurs & 10.0 & 33.9 & 23.8 & 13.4 & 8 & 5.9 \\
\hline Toronto Raptors & 10.6 & 32.6 & 18.5 & 12.7 & 8.3 & 4.9 \\
\hline Utah Jazz & 9.4 & 33.8 & 20.1 & 13.6 & 6.7 & 5 \\
\hline Washington Wizards & 10.3 & 32.6 & 23.9 & 14.2 & 8.5 & 4.1 \\
\hline
\end{tabular}

Notes:

OREB17 is the 2016-17 regular season offensive rebounds per game average for each team.

DREB17 is the 2016-17 regular season defensive rebounds per game average for each team.

ASTAV17 is the 2016-17 regular season total assists per game average for each team.

TOV17 is the 2016-17 regular season turnovers per game average for each team.

STL17 is the 2016-17 regular season steals per game average for each team.

BLK17 is the 2016-17 regular season blocked shots per game average for each team. 
Vol. 7, No. $2 \quad$ Fullerton et al.: Empirical Mysteries of the 2016-17 NBA Regular Season

Table 3.

\begin{tabular}{|l|c|c|c|c|c|}
\hline & & & & & \\
\hline Team & COACH17 & TOTFINE17 & AGE17 & EXP17 & PYRL17 \\
\hline Atlanta Hawks & $\$ 2,000,000$ & $\$ 186,849$ & 28.4 & 6.2 & $\$ 91,216,857$ \\
\hline Boston Celtics & $\$ 3,670,000$ & $\$ 124,000$ & 25.5 & 4.2 & $\$ 93,035,160$ \\
\hline Brooklyn Nets & $\$ 2,500,000$ & $\$ 27,000$ & 25.8 & 3.5 & $\$ 83,943,358$ \\
\hline Charlotte Hornets & $\$ 2,000,000$ & $\$ 31,000$ & 26.1 & 4.4 & $\$ 102,675,926$ \\
\hline Chicago Bulls & $\$ 5,000,000$ & $\$ 217,175$ & 26.1 & 3.9 & $\$ 92,571,387$ \\
\hline Cleveland Cavaliers & $\$ 3,000,000$ & $\$ 50,000$ & 29.9 & 8.5 & $\$ 127,254,579$ \\
\hline Dallas Mavericks & $\$ 7,000,000$ & $\$ 79,000$ & 27.2 & 4.1 & $\$ 104,042,028$ \\
\hline Denver Nuggets & $\$ 2,000,000$ & $\$ 36,000$ & 26.3 & 4.9 & $\$ 82,573,997$ \\
\hline Detroit Pistons & $\$ 7,000,000$ & $\$ 89,899$ & 25.6 & 3.7 & $\$ 108,967,919$ \\
\hline Golden State Warriors & $\$ 5,000,000$ & $\$ 114,000$ & 28.2 & 6.7 & $\$ 101,725,589$ \\
\hline Houston Rockets & $\$ 4,000,000$ & $\$ 76,000$ & 26.2 & 4.7 & $\$ 90,996,769$ \\
\hline Indiana Pacers & $\$ 5,426,275$ & $\$ 88,000$ & 26.9 & 5.7 & $\$ 94,008,504$ \\
\hline LA Clippers & $\$ 10,000,000$ & $\$ 109,000$ & 29.7 & 8.3 & $\$ 116,237,542$ \\
\hline Los Angeles Lakers & $\$ 5,000,000$ & $\$ 120,000$ & 25.8 & 4.4 & $\$ 95,226,183$ \\
\hline Memphis Grizzlies & $\$ 2,550,000$ & $\$ 45,000$ & 27.5 & 5.5 & $\$ 111,045,893$ \\
\hline Miami Heat & $\$ 3,000,000$ & $\$ 101,000$ & 27.3 & 5.1 & $\$ 101,818,405$ \\
\hline Milwaukee Bucks & $\$ 6,000,000$ & $\$ 81,000$ & 25.7 & 4.3 & $\$ 94,012,121$ \\
\hline Minnesota Timberwolves & $\$ 10,000,000$ & $\$ 22,000$ & 25.7 & 3.6 & $\$ 81,621,379$ \\
\hline New Orleans Pelicans & $\$ 3,437,500$ & $\$ 214,238$ & 26.3 & 4 & $\$ 101,707,386$ \\
\hline New York Knicks & $\$ 5,000,000$ & $\$ 3,282,364$ & 27 & 3.9 & $\$ 103,595,894$ \\
\hline Oklahoma City Thunder & $\$ 6,000,000$ & $\$ 289,095$ & 25.8 & 3.7 & $\$ 91,339,949$ \\
\hline Orlando Magic & $\$ 5,500,000$ & $\$ 46,000$ & 25.5 & 3.8 & $\$ 104,110,336$ \\
\hline Philadelphia 76ers & $\$ 2,000,000$ & $\$ 47,000$ & 24.6 & 2.1 & $\$ 85,763,788$ \\
\hline Phoenix Suns & $\$ 2,500,000$ & $\$ 238,851$ & 25.5 & 4.5 & $\$ 85,115,778$ \\
\hline Portland Trail Blazers & $\$ 5,000,000$ & $\$ 44,000$ & 24.6 & 3.1 & $\$ 112,416,239$ \\
\hline Sacramento Kings & $\$ 4,000,000$ & $\$ 730,487$ & 26.1 & 4.5 & $\$ 96,043,092$ \\
\hline San Antonio Spurs & $\$ 11,000,000$ & $\$ 12,000$ & 28.9 & 6.6 & $\$ 108,640,621$ \\
\hline Toronto Raptors & $\$ 6,000,000$ & $\$ 201,364$ & 25.5 & 3.8 & $\$ 108,664,969$ \\
\hline Utah Jazz & $\$ 3,000,000$ & $\$ 57,000$ & 26.3 & 4.7 & $\$ 80,598,193$ \\
\hline Washington Wizards & $\$ 7,000,000$ & $\$ 266,000$ & 25.7 & 3.8 & $\$ 102,334,382$ \\
\hline
\end{tabular}

Notes:

COACH17 is the 2016-17 regular season head coach salary for each team with an authors estimate provided for the head coach salary of the Indiana Pacers.

TOTFINE17 is the 2016-17 regular season total of all player fines for each team.

AGE17 is the 2016-17 regular season average age of players for each team.

EXP17 is the 2016-17 average number of years the players on each team have in the NBA.

PYRL17 is the 2016-17 total players payroll for each team. 
Table 4.

\begin{tabular}{|l|c|}
\hline & PSD17 \\
\hline Team & $\$ 5,334,572$ \\
\hline Atlanta Hawks & $\$ 6,129,341$ \\
\hline Boston Celtics & $\$ 3,704,970$ \\
\hline Brooklyn Nets & $\$ 5,914,903$ \\
\hline Charlotte Hornets & $\$ 7,017,125$ \\
\hline Chicago Bulls & $\$ 8,883,652$ \\
\hline Cleveland Cavaliers & $\$ 6,601,351$ \\
\hline Dallas Mavericks & $\$ 4,131,973$ \\
\hline Denver Nuggets & $\$ 6,309,190$ \\
\hline Detroit Pistons & $\$ 7,047,165$ \\
\hline Golden State Warriors & $\$ 6,891,170$ \\
\hline Houston Rockets & $\$ 5,181,032$ \\
\hline Indiana Pacers & $\$ 7,810,465$ \\
\hline LA Clippers & $\$ 5,355,228$ \\
\hline Los Angeles Lakers & $\$ 7,758,962$ \\
\hline Memphis Grizzlies & $\$ 6,925,492$ \\
\hline Miami Heat & $\$ 5,386,981$ \\
\hline Milwaukee Bucks & $\$ 3,788,828$ \\
\hline Minnesota Timberwolves & $\$ 5,729,209$ \\
\hline New Orleans Pelicans & $\$ 7,529,957$ \\
\hline New York Knicks & $\$ 6,464,880$ \\
\hline Oklahoma City Thunder & $\$ 5,959,714$ \\
\hline Orlando Magic & $\$ 3,385,426$ \\
\hline Philadelphia 76ers & $\$ 4,445,831$ \\
\hline Phoenix Suns & $\$ 7,144,805$ \\
\hline Portland Trail Blazers & $\$ 4,170,870$ \\
\hline Sacramento Kings & $\$ 6,893,417$ \\
\hline San Antonio Spurs & $\$ 7,158,464$ \\
\hline Toronto Raptors & $\$ 4,835,127$ \\
\hline Utah Jazz & $\$ 6,641,051$ \\
\hline Washington Wizards & \\
\hline & \\
\hline & \\
\hline
\end{tabular}

Notes:

PSD17 is the 2016-17 standard deviation of the player payroll for each team. 
